Article

\title{
In Vitro Effects of Lactobacillus plantarum LN66 and Antibiotics Used Alone or in Combination on Helicobacter pylori Mature Biofilm
}

\author{
Jianfu Ji and Hong Yang *
}

Citation: Ji, J.; Yang, H. In Vitro Effects of Lactobacillus plantarum LN66 and Antibiotics Used Alone or in Combination on Helicobacter pylori Mature Biofilm. Microorganisms 2021, 9, 424. https://doi.org/10.3390/ microorganisms 9020424

Academic Editor: Yoshio Yamaoka Received: 10 January 2021

Accepted: 30 January 2021

Published: 18 February 2021

Publisher's Note: MDPI stays neutral with regard to jurisdictional claims in published maps and institutional affiliations.

Copyright: (c) 2021 by the authors. Licensee MDPI, Basel, Switzerland. This article is an open access article distributed under the terms and conditions of the Creative Commons Attribution (CC BY) license (https:// creativecommons.org/licenses/by/ $4.0 /)$.
State Key Laboratory of Microbial Metabolism, School of Life Sciences and Biotechnology, Shanghai Jiao Tong University, Shanghai 201100, China; jijianfu@sjtu.edu.cn

* Correspondence: hongyang@sjtu.edu.cn; Tel.: +86-021-34205343

\begin{abstract}
Helicobacter pylori is a gastrointestinal pathogen with high prevalence that harms human health. Studies have shown that $H$. pylori can form antibiotic-tolerant biofilms, which may interfere with the efficacy of clinical antibiotic therapy. Probiotics can antagonize planktonic and biofilm pathogen cells and thus may play an auxiliary role in H. pylori antibiotic therapy. However, the effects of different probiotic strains and antibiotic combinations on $H$. pylori biofilms need to be further investigated. We determined the cell viability of $H$. pylori mature biofilms after treatment with Lactobacillus plantarum LN66 cell-free supernatant (CFS), clarithromycin (CLR), and levofloxacin (LVX) alone or in combination by the XTT method. Biofilm cells were observed by scanning electron microscopy (SEM) and confocal laser scanning microscopy (CLSM). Subsequently, protein and polysaccharide concentrations in biofilm extracellular polymeric substances (EPSs) were quantitatively detected by the Bradford method and the phenol-sulfate method. The results showed that LN66 CFS had an eradication effect on mature H. pylori biofilm. When used in combination with CLR, LN66 CFS significantly attenuated the eradication effect of CLR on biofilms; in contrast, when used in combination with LVX, LN66 CFS enhanced the disrupting effect of LVX. We speculate that the different effects of CFS and antibiotic combinations on biofilms may be related to changes in the content of proteins and polysaccharides in EPS and that the combination of CFS and CLR might promote the secretion of EPS, while the combination of CFS and LVX might have the opposite effect. Accordingly, we suggest that supplementation with L. plantarum LN66 may provide additional help when therapy involving LVX is used for clinical H. pylori biofilm eradication, whereas it may impair CLR efficacy when therapy involving CLR is used.
\end{abstract}

Keywords: Lactobacillus plantarum; Helicobacter pylori; biofilm; clarithromycin; levofloxacin

\section{Introduction}

Helicobacter pylori has infected more than half of the world's population, with infection rates exceeding 80\% in China and some Eastern European and South American countries [1]. The close relationship between $H$. pylori infection and the development of chronic gastritis, peptic ulcer disease, and gastric cancer led to its classification as a type I carcinogen by the World Health Organization (WHO) in 1994 [2]. The high prevalence of this pathogen and the harm to human health have prompted most clinical guidelines to recommend H. pylori eradication as a good option for the prevention and treatment of a series of gastrointestinal diseases [3]. Although multidrug regimens such as triple therapy have been used in clinical practice, factors such as inappropriate antibiotic use and biofilm formation make eradication an increasingly challenging task.

Biofilm formation may play a crucial role in $H$. pylori long-term colonization and reinfection [4]. Biofilms, as barriers of bacterial cells, can defend against drugs and the host immune system. Secretion of extracellular polymeric substances (EPS), low cellular metabolic activity inside the matrix and upregulation of efflux pump gene expression 
enhance the tolerance of biofilm cells to harsh environments [5]. In some cases, the antibiotic concentration needed to eradicate bacterial biofilm cells can be 100-1000 times higher than that needed to eradicate planktonic cells [6]. Therefore, the existence of biofilms may increase the drug dose required for $H$. pylori clinical eradication, thus exacerbating the increasing prevalence of drug-resistant strains. Exploration of therapeutic regimens that eradicate $H$. pylori biofilms effectively could enable the development of a new approach for $H$. pylori treatment, providing new strategies for improvement of $H$. pylori eradication rates.

Probiotics are defined as live microorganisms that, when administered in adequate amounts, confer health benefits on the host [3]. Probiotic preparations are deemed safe and can regulate the human gastrointestinal flora and immune system [7]. Recently, studies have indicated that probiotics can inhibit pathogen biofilm formation by inhibiting pathogen growth and interfering with the quorum sensing system or by producing antibacterial substances to disrupt the mature biofilm [8]. In addition, taking probiotic preparations seems to be a good option for eradication of $H$. pylori biofilms. However, clinical results have shown that taking probiotics alone cannot meet the need for $\mathrm{H}$. pylori clinical eradication. The use of probiotics adjuncts in combination with certain antibiotic therapies may achieve better therapeutic effects than the use of probiotics alone [3]. This is consistent with the findings of in vitro experiments that probiotic metabolites and certain antibiotics have synergistic antibacterial effects [9]. However, there have been few studies investigating the interactions and mechanisms underlying probiotic-antibiotic combinations from the perspective of $H$. pylori biofilms. We intended to evaluate the eradication effects of $L$. plantarum LN66 cell-free supernatant (CFS), clarithromycin (CLR), and levofloxacin (LVX) on H. pylori biofilms, either alone or in combination, and to explore the potential basic mechanisms in order to provide a basis for better H. pylori biofilm eradication with reduced antibiotic dosages and improved drug precision in the clinic.

\section{Materials and Methods}

\subsection{Bacterial Strain, Medium and Growth Conditions}

L. plantarum LN66 and three reference strain, L. rhamnosus GG, L. paracasei ATCC334 and L. reuteri DSM20016 were provided by Jiaxing Innocul—Probiotics Co., Ltd. (Jiaxing, Zhejiang, China). H. pylori ATCC43504, Escherichia coli ATCC25922, Staphylococcus aureus ATCC29213, Shigella sonnei ATCC25931, Salmonella tyhimurium ATCC14028 were purchased from the American Type Culture Collection (ATCC). All Lactobacillus strains were cultured in modified de Man Rogosa Sharpe broth [10] (tryptone $10 \mathrm{~g}$, beef extract powder $10 \mathrm{~g}$, yeast extract $5 \mathrm{~g}$, glucose $20 \mathrm{~g}, \mathrm{~K}_{2} \mathrm{HPO}_{4} 2 \mathrm{~g}$, ammonium citrate $2 \mathrm{~g}, \mathrm{MgSO}_{4} \cdot 7 \mathrm{H}_{2} \mathrm{O} 0.2 \mathrm{~g}$, $\mathrm{MnSO}_{4} \cdot 4 \mathrm{H}_{2} \mathrm{O} 0.2 \mathrm{~g}$, brought to a volume of $1 \mathrm{~L}$ with distilled water; for solid culture, $1.5 \%$ agar powder was added) for $12-24 \mathrm{~h}$ at $37^{\circ} \mathrm{C}$. For solid culture, $H$. pylori was inoculated onto Columbia Blood Agar plates containing 10\% (v/v) defibrinated sheep blood (DSB) for $3-5 \mathrm{~d}$ at $37^{\circ} \mathrm{C}$ under microaerobic conditions (MGC, Tokyo, Japan). For liquid culture, H. pylori was inoculated into Brucella Broth (BB) containing 10\% $(v / v)$ fetal bovine serum (FBS) for $1-3 \mathrm{~d}$ at $37^{\circ} \mathrm{C}$ under microaerobic conditions. E. coli, S. aureus, S. sonnei, and S. tyhimurium were cultured in Brain Heart Infusion (BHI) medium for $12-24 \mathrm{~h}$ at $37^{\circ} \mathrm{C}$.

\subsection{MICs of Antibiotics}

The minimum inhibitory concentrations (MICs) of CLR and LVX (Macklin, Shanghai, China) were determined based on a broth dilution assay with slight modifications [5]. Briefly, H. pylori cells and two antibiotics were all diluted in BB containing $10 \%$ FBS, and the cells were adjusted to a final concentration of approximately $5 \times 10^{6} \mathrm{CFU} / \mathrm{mL}$. Then, $100 \mu \mathrm{L}$ bacterial suspension was added to the wells of 96-well plates containing two-fold serial antibiotic dilutions to a total volume of $200 \mu \mathrm{L}$. The plates were incubated at $37^{\circ} \mathrm{C}$ under microaerobic conditions for $3 \mathrm{~d}$, and then the $\mathrm{OD}_{600 \mathrm{~nm}}$ values were analyzed using a microplate reader (Tecan, Männedorf, Switzerland). The MIC value was defined as the lowest concentration of the antimicrobial agent that inhibited the growth of bacteria. 


\subsection{Collection of LN66 CFS}

To collect the LN66 CFS, the strain was inoculated with modified MRS broth, and the fermentation broth was collected when the cell concentration reached approximately $1 \times 10^{9} \mathrm{CFU} / \mathrm{mL}$. Then, the bacterial culture was centrifuged at $4{ }^{\circ} \mathrm{C}$ and $7600 \mathrm{rpm}$ for $10 \mathrm{~min}$, and CFS was obtained after filtration with a $0.22 \mu \mathrm{m}$ filter membrane.

\subsection{Characterization of L. plantarum LN66}

LN66 was identified by $16 \mathrm{~S}$ rRNA gene sequencing, universal primers $27 \mathrm{~F}$ and $1492 \mathrm{R}$ were used to amplify the 16S rRNA gene. The resistance of LN66 to simulated gastric juice was tested by the method of De Souza [11]. Auto-aggregation and hydrophobicity assay were performed according to Zuo [12]. Antimicrobial activity of LN66 CFS was evaluated by agar-well diffusion assay, five pathogens, H. pylori ATCC43504, E. coli ATCC25922, S. aureus ATCC29213, S. sonnei ATCC25931, S. tyhimurium ATCC14028 were used as indicator strains. The protein content of LN66 CFS was measured with a Bradford protein assay kit (Sangon, Shanghai, China), the polysaccharide content was measured by the phenol-sulfate method, and the $\mathrm{pH}$ value was measured [13,14]. L. rhamnosus GG, L. paracasei ATCC334, L. reuteri DSM20016 were used as positive controls for the above assays.

\subsection{MIC of LN66 CFS}

To determine the MIC value of LN66 CFS, we performed the method described by Pelyuntha with some modifications [15]. The cell concentrations and the culture system were the same as described above for the antibiotic MIC assay except that the two-fold dilutions of antibiotics were replaced with $5-50 \%(v / v)$ CFS diluted in BB containing $10 \%$ FBS. The plates were incubated at $37^{\circ} \mathrm{C}$ under microaerobic conditions for $3 \mathrm{~d}$, and then the $\mathrm{OD}_{600 \mathrm{~nm}}$ was analyzed using a microplate reader.

\subsection{FICS of Antibiotics and CFS}

The FIC values of antibiotics and LN66 CFS used in combination were determined based on the method described by Yang [16]. Basically, H. pylori was inoculated into the culture system for MIC assay, except that the single drug was replaced by different concentrations of CLR $+\mathrm{CFS}$ or LVX $+\mathrm{CFS}$. The plates were incubated at $37^{\circ} \mathrm{C}$ under microaerobic conditions for $3 \mathrm{~d}$, and then the $\mathrm{OD}_{600 \mathrm{~nm}}$ was analyzed using a microplate reader.

$$
\mathrm{FICi}=\mathrm{FIC}(\mathrm{A})+\mathrm{FIC}(\mathrm{B})=(\mathrm{A}) /(\mathrm{MICA})+(\mathrm{B}) / \mathrm{MIC}(\mathrm{B})
$$

FIC values of 0.5 or less, $0.75,1.0$, and 2.0 or more are defined as partially synergistic, additive, indifferent, and antagonistic, respectively.

\subsection{Construction of Biofilm}

An H. pylori biofilm was constructed by the colony biofilm method as described by Ge [17]. Briefly, sterile nitrocellulose (NC) membranes (Millipore, Burlington, MA, USA) approximately $1 \mathrm{~cm} \times 1 \mathrm{~cm}$ in size were placed on CA containing $10 \%$ DSB. The H. pylori cell concentration was adjusted to approximately $5 \times 10^{7} \mathrm{CFU} / \mathrm{mL}$, and then $20 \mu \mathrm{L}$ of the bacterial suspension was inoculated onto each NC membrane. After drying the NC membrane for $10 \mathrm{~min}$, the plates were turned over and incubated at $37^{\circ} \mathrm{C}$ microaerobic conditions for $3 \mathrm{~d}$ to obtain mature $H$. pylori biofilms.

\subsection{Analysis of CFS Effectiveness after Different Treatments}

Analysis of CFS effectiveness after different treatments was based on the method described by Chen with some modifications, and biofilm cell viability was measured by the XTT method $[18,19]$. Untreated raw CFS was divided into three groups: one was digested with $1 \mathrm{mg} / \mathrm{mL}$ proteinase $\mathrm{K}$ at $37^{\circ} \mathrm{C}$ for $1 \mathrm{~h}\left(95^{\circ} \mathrm{C}\right.$ for $1 \mathrm{~min}$ after incubation to inactivate proteinase $\mathrm{K}$ ), one was adjusted to $\mathrm{pH} 6.5$ with $1 \mathrm{M} \mathrm{NaOH}$, and one was heat-treated at 
$115^{\circ} \mathrm{C}$ for $20 \mathrm{~min}$. Then, the pretreated CFS and modified MRS broth were diluted to the same concentration as the untreated CFS MIC.

The $2 \mathrm{~mL}$ pretreated CFS dilutions, untreated CFS dilutions, and modified MRS dilutions were added to 24 -well plates, and then the mature biofilms were transferred to the corresponding wells. The inoculated plates were incubated at $37^{\circ} \mathrm{C}$ under microaerobic conditions for $24 \mathrm{~h}$. Then, the suspensions were aspirated, and the NC membranes were washed thrice carefully with PBS. After natural drying, the NC membranes were transferred to new 24-well plates; $600 \mu \mathrm{L}$ of BB containing $10 \%$ FBS and $200 \mu \mathrm{L}$ of $1 \mathrm{mg} / \mathrm{mL}$ XTT solution (containing 5\% $0.4 \mathrm{mM}$ menadione) (Macklin) were added, the membranes were incubated at $37^{\circ} \mathrm{C}$ under microaerobic dark conditions for $3 \mathrm{~h}$, and the $\mathrm{OD}_{492 \mathrm{~nm}}$ values were analyzed with a UV2802 spectrophotometer (UNICO, Shanghai, China).

\subsection{Drug Sensitivity before and after Biofilm Formation}

An H. pylori planktonic cell susceptibility assay was carried out. Briefly, the H. pylori cell concentration was adjusted to approximately $5 \times 10^{7} \mathrm{CFU} / \mathrm{mL}$, and $1 \mathrm{~mL}$ of bacterial suspension was added to 24-well plates followed by $1 \mathrm{~mL}$ of CLR, LVX, or CFS at different dilutions. In the final system, the $H$. pylori cell concentration was $2.5 \times 10^{7} \mathrm{CFU} / \mathrm{mL}$; the CLR or LVX concentration was $1 \times \mathrm{MIC}, 4 \times \mathrm{MIC}, 16 \times \mathrm{MIC}$, or $64 \times \mathrm{MIC}$; the CFS concentration was $1 \times \mathrm{MIC}, 1 / 2 \times \mathrm{MIC}, 1 / 4 \times \mathrm{MIC}$, or $1 / 8 \times \mathrm{MIC}$. The inoculated plates were incubated at $37^{\circ} \mathrm{C}$ under microaerobic conditions for $24 \mathrm{~h}$. Then, the suspensions were centrifuged, and the supernatant was discarded to collect the pelleted cells. The bacteria were washed thrice with PBS and resuspended in $600 \mu \mathrm{L}$ of BB containing $10 \%$ FBS, and cell viability was determined by the XTT method.

An $H$. pylori biofilm cell susceptibility assay was carried out. Briefly, $2 \mathrm{~mL}$ of each of the above CLR, LVX, and CFS dilutions was added to 24-well plates, and the mature biofilms were transferred to the corresponding wells. The inoculated plates were incubated at $37^{\circ} \mathrm{C}$ under microaerobic conditions for $24 \mathrm{~h}$. The biofilm cell viability was determined as mentioned above.

\subsection{Effect of CFS Combined with Antibiotics on H. pylori Biofilm Viability}

In the separate antibiotic and CFS groups, $2 \mathrm{~mL}$ of CLR or LVX diluted to a concentration of $1 \times$ MIC or CFS diluted to a concentration of $1 / 2 \times$ MIC was added to a 24-well plate. In the antibiotic and CFS combination group, the $2 \mathrm{~mL}$ final system contained a CLR concentration of $1 \times \mathrm{MIC}$ and a CFS concentration of $1 / 2 \times$ MIC or an LVX concentration of $1 \times$ MIC and a CFS concentration of $1 / 2 \times$ MIC. The mature biofilms were transferred to the corresponding wells. The inoculated plates were incubated at $37^{\circ} \mathrm{C}$ under microaerobic conditions for $24 \mathrm{~h}$. The biofilm cell viability was determined as mentioned above.

\subsection{Effect of CFS Combined with Antibiotics on H. pylori Biofilm EPS}

Extraction of $H$. pylori biofilm EPS was performed on the basis of the ultrasonic centrifugation method described by Kang with some modifications [20]. The different groups of pretreated biofilms mentioned above were washed thrice with PBS. After natural drying, $1 \mathrm{~mL}$ of PBS was added, and the biofilm matrix was sonicated at $37^{\circ} \mathrm{C}$ for $15 \mathrm{~min}$ and then centrifuged at $4{ }^{\circ} \mathrm{C}$ and $10,000 \mathrm{rpm}$ for $30 \mathrm{~min}$. The supernatant was collected for the determination of protein and polysaccharide concentrations in EPS. The protein concentrations were quantitatively measured with a Bradford protein assay kit, and the polysaccharide concentrations were measured by the phenol-sulfate method.

\subsection{Effect of CFS Combined with Antibiotics on H. pylori Biofilm SEM Observations}

The different groups of pretreated biofilms mentioned above were washed thrice with PBS. After natural drying, the biofilms were transferred into 12-well plates and fixed with $2 \mathrm{~mL}$ of $2.5 \%$ glutaraldehyde solution at $4{ }^{\circ} \mathrm{C}$ for $12 \mathrm{~h}$. The fixed biofilms were sequentially dehydrated by adding a gradient of 25\%,50\%,75\%,95\%, and 100\% ethanol for $15 \mathrm{~min}$ per concentration. The dehydrated biofilms were then dried in a CPD 300 automatic 
critical-point dryer (Leica, Weztlar, Germany). After sputter coating with gold, the biofilms were observed under a S3400II scanning electron microscope (Hitachi, Tokyo, Japan).

\subsection{Effect of CFS Combined with Antibiotics on H. pylori Biofilm CLSM Observations}

The different groups of pretreated biofilms mentioned above were washed thrice with PBS. After drying naturally, the biofilms were transferred into 12-well plates and stained with 2 mL of LIVE/DEAD BacLight Bacterial Viability Kit reagent (Invitrogen, Carlsbad, CA, USA) in a darkroom for $20 \mathrm{~min}$. Then, the dye was aspirated, and the biofilms were washed thrice with PBS before being fixed on coverslips. The biofilms were observed under a TCS SP8 STED 3X laser confocal microscope (Leica, Weztlar, Germany).

\subsection{Effect of CFS Combined with Antibiotics on H. pylori Biofilm Virulence Gene Expression}

Total RNA was extracted using a TransZol Up Plus RNA Kit (Transgen, Beijing, China). Then, cDNA was synthesized using a PrimeScript RT Reagent Kit with gDNA Eraser (Takara, Kyoto, Japan). Finally, TB Green Premix Ex Taq ${ }^{\mathrm{TM}}$ II (Takara, Kyoto, Japan) was added for fluorescence detection on a qTOWER3G quantitative PCR apparatus (Analytik Jena, Jena, Germany). The primers used for qPCR are listed in Table 1. The expression of each gene was normalized to the 16S rRNA expression as an internal control, and the relative expression was calculated using the $2^{-\Delta \Delta \mathrm{CT}}$ method.

Table 1. Primers for qPCR.

\begin{tabular}{cc}
\hline Genes & Sequences $\mathbf{( 5}^{\prime} \mathbf{- 3}^{\prime} \mathbf{)}$ \\
\hline$c a g A-\mathrm{F}$ & GCAAGTGGTTTGGGTGGTGTAGG \\
$c a g A-\mathrm{R}$ & CCGCCGAGATCATCAATCGTAGC \\
$v a c A-\mathrm{F}$ & AGCGAGCGGGCGTTCTTTATTG \\
$v a c A-\mathrm{R}$ & GGTATCCGTGCCAGCCTTAAACTC \\
$16 \mathrm{~s}$ rRNA-F & GGCGACCTGCTGGAACATTACTG \\
16 rRNA-R & CATCGTTTAGGGCGTGGACTACC \\
\hline
\end{tabular}

\subsection{Effect of CFS Combined with Antibiotics on H. pylori Biofilm Live Cell Dispersion}

The effects of different combinations on biofilm live cell dispersion were assessed by measuring cell viability in suspension. In brief, $600 \mu \mathrm{L}$ suspensions were taken from wells containing the pretreated biofilms in the different groups mentioned above, and the cell viability was determined by the XTT method.

\subsection{Effect of CFS Combined with Antibiotics on H. pylori Planktonic Cell Viability}

The $H$. pylori cell concentration was adjusted to approximately $5 \times 10^{7} \mathrm{CFU} / \mathrm{mL}$, and $1 \mathrm{~mL}$ of bacterial suspension was added to 24-well plates followed by $1 \mathrm{~mL}$ of CLR, LVX, or CFS dilution separately or in combination to achieve the abovementioned combinations and concentrations for the biofilm assay. The inoculated plates were incubated at $37^{\circ} \mathrm{C}$ under microaerobic conditions for $24 \mathrm{~h}$. The planktonic cell viability was determined as mentioned above.

\subsection{Statistical Analysis}

Each assay was performed in triplicate, and the data are expressed as the means \pm standard deviations. The differences between the groups were examined by one-way analysis of variance (ANOVA) followed by Turkey's Multiple Comparison test using Minitab 18.1 software (Minitab, State College, PA, USA). A $p$-value of $<0.05$ was considered to indicate statistical significance. 


\section{Results}

\subsection{MICs and Characterization of LN66}

The MIC values of CLR, LVX, and LN66 CFS were determined by the broth dilution method. As shown in Table 2, the MIC values of CLR and LVX were 0.063 and $0.250 \mu \mathrm{g} / \mathrm{mL}$, respectively.

Table 2. Minimal inhibitory concentrations (MICs) of CLR and LVX.

\begin{tabular}{cc}
\hline Antibiotics & MICs $(\mu \mathrm{g} / \mathrm{mL})$ \\
\hline CLR & 0.063 \\
LVX & 0.250 \\
\hline
\end{tabular}

LN66 was identified as L. plantarum by $16 \mathrm{~S}$ rRNA gene sequencing (Supplementary Figure S1). The strain can survive at $\mathrm{pH} 2.0$ simulated gastric juice for $2 \mathrm{~h}$, and holds a moderate hydrophobicity and auto-aggregation capabilities compared to the reference strains (Supplementary Figures S2 and S3).

After cultivated to approximately $1 \times 10^{9} \mathrm{CFU} / \mathrm{mL}$, LN66 CFS was collected. LN66 CFS had significant inhibitory activities against H. pylori, S. aureus and S. sonnei, compared to MRS medium and the reference strain, and shows the capability of antagonizing E. coli and S. tyhimurium (Supplementary Table S1).

Results showed that CFS diluted with BB containing 10\% FBS to a final concentration of $12.5 \%$ was the lowest dilution that could inhibit the growth of $H$. pylori, so the MIC value of LN66 CFS was defined as $12.5 \%$.

Moreover, the FICs, see in Table 3, shows that the effect between CLR + CFS is antagonist, and the effect between LVX + CFS is additive.

Table 3. Fractional inhibitory concentrations (FICs) of antibiotics and CFS.

\begin{tabular}{ccc}
\hline Combinations & FICs & Effect \\
\hline CLR + CFS & $3(0.125 \mu \mathrm{g} / \mathrm{mL}, 12.5 \%)$ & Antagonist \\
LVX + CFS & $1(0.125 \mu \mathrm{g} / \mathrm{mL}, 6.25 \%)$ & Additive \\
\hline
\end{tabular}

3.2. The Eradication Effect of LN66 CFS on H. pylori Mature Biofilms Is Derived Mainly from Heat-Stable Peptides

The viability of $H$. pylori biofilm cells after $24 \mathrm{~h}$ of CFS treatment was determined by the XTT method, with a higher $\mathrm{OD}_{492 \mathrm{~nm}}$ value representing greater biofilm viability. We first divided the LN66 CFS into three groups that were heat-treated, neutralized and proteinase K-treated. Then, untreated CFS, pretreated CFS, and modified MRS broth were all diluted to $12.5 \%$, and the H. pylori mature biofilms in each group were incubated for $24 \mathrm{~h}$.

The results showed that L. plantarum LN66 CFS had an eradication effect on $H$. pylori biofilms, and this effect was not derived from the modified MRS broth but from the LN66 metabolized derivatives. Additionally, although the LN66 CFS hold the lowest protein, polysaccharide contents and $\mathrm{pH}$ value compared to MRS medium and the references' CFS (Supplementary Table S2), the ability of LN66 CFS to eradicate H. pylori biofilm did not mainly depend on its low pH value. As shown in Figure 1, the OD492 nm measured at $24 \mathrm{~h}$ in the control group was $0.265 \pm 0.002$, which was not significantly different $(p<0.05)$ from the OD492 $\mathrm{nm}$ in the modified MRS group, whereas the viability was significantly lower in the four CFS groups than in the control group. In addition, different pretreatment methods caused different impacts on the eradication capacity of CFS. The only pretreatment that did not weaken the CFS eradication capacity was the heat treatment; the heat-treated group had the strongest biofilm eradication capacity among pretreatment groups, exhibiting the same capacity as the untreated group; the heat-treated and untreated groups had OD492 $\mathrm{nm}$ values of $0.054 \pm 0.002$ and $0.056 \pm 0.004$, respectively. The remaining two pretreatment groups had significantly weaker eradication capacity than the untreated group. Proteinase 
$\mathrm{K}$ treatment reduced the CFS eradication capacity to a great extent, resulting in an OD492 $\mathrm{nm}$ of $0.188 \pm 0.003$. Neutralization, on the other hand, caused CFS to lose less of its eradication capacity, resulting in an OD492 $\mathrm{nm}$ of $0.093 \pm 0.005$.

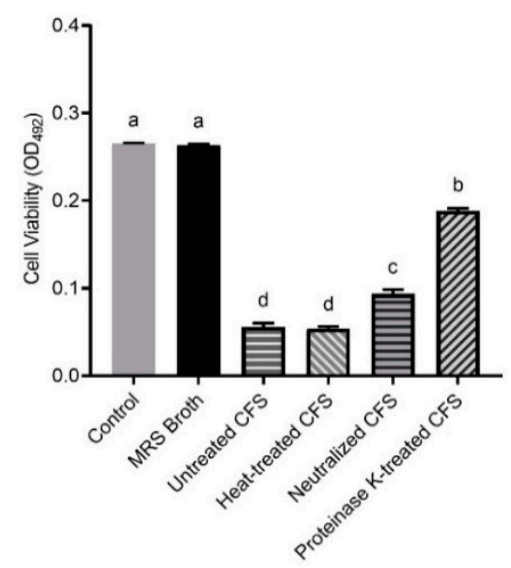

Figure 1. Eradication effects of untreated LN66 CFS, three types of pretreated CFS and modified MRS broth at $12.5 \%$ dilutions on Helicobacter pylori mature biofilms. The experimental data are expressed as the mean \pm standard deviation $(n=3)$, and groups marked with different superscript letters are significantly different $(p<0.05)$.

In addition, Figure 2 shows that the capacity of LN66 CFS to eradicate H. pylori biofilm was not significantly weakened $(p<0.05)$ when the CFS was diluted from $1 / 2 \times$ MIC to $1 / 8 \times$ MIC. When the concentration decreased from $1 \times$ MIC to $1 / 2 \times$ MIC, the eradication capacity of CFS decreased significantly, but when the concentration continued to drop to $1 / 4 \times$ MIC or $1 / 8 \times$ MIC, the eradication capacity of CFS remained unchanged.

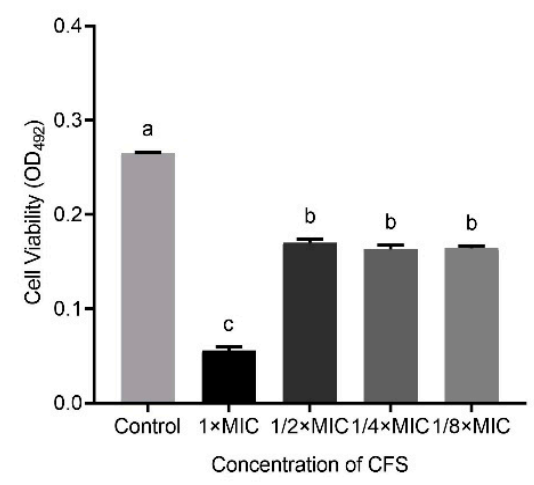

Figure 2. Eradication effects of untreated LN66 CFS at $1 \times \mathrm{MIC}, 1 / 2 \times \mathrm{MIC}, 1 / 4 \times \mathrm{MIC}$, and $1 / 8 \times$ MIC dilutions on $H$. pylori mature biofilms. The experimental data are expressed as the mean \pm standard deviation $(n=3)$, and groups marked with different superscript letters are significantly different $(p<0.05)$.

\subsection{H. pylori Sensitivity to High Concentrations of CLR and LVX Is Reduced after Mature Biofilm Formation}

To investigate the sensitivity of $H$. pylori to CLR and LVX before and after biofilm formation, we tested four groups with different dilutions $(1 \times \mathrm{MIC}, 4 \times \mathrm{MIC}, 16 \times \mathrm{MIC}$, and $64 \times \mathrm{MIC}$ ) of each antibiotic. Cell viability after $24 \mathrm{~h}$ of treatment with different concentrations of CLR or LVX was measured by the XTT method described above.

As shown in Figure 3, H. pylori was less sensitive to high concentrations of CLR and LVX after the formation of biofilms than before the formation of biofilms. At a $1 \times$ MIC or $4 \times$ MIC dilution, the capacity of CLR to eradicate H. pylori biofilm cells was significantly weaker than the capacity of CLR to eradicate the corresponding planktonic cells $(p<0.05)$. In the LVX group, biofilm cell viability was significantly lower than planktonic cell viability 
at a $1 \times$ MIC dilution, and there was no significant difference in viability between the two types of cells at a $4 \times$ MIC dilution. Furthermore, we found that the $H$. pylori biofilm viability after $24 \mathrm{~h}$ of $16 \times$ MIC or $64 \times$ MIC CLR or LVX treatment was significantly higher than that of the corresponding planktonic cells. Surprisingly, the biofilm cell viability of the control group was significantly lower than the planktonic cell viability of the control group, which may have been due to the specificity of the colony biofilm construction approach used in our study. Unlike microtiter plate biofilm cultured in broth medium, colony biofilm is established in agar medium, thus the colony biofilm, with large biomass, needs to adapt to the liquid environment, whereas the planktonic assay inoculated H. pylori culture suspension into the BB broth directly [21].

CLR

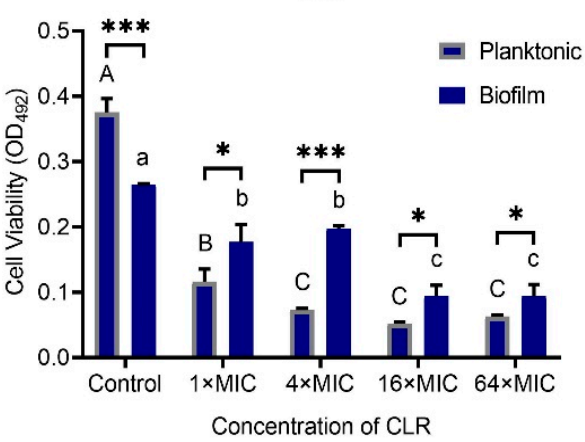

LVX

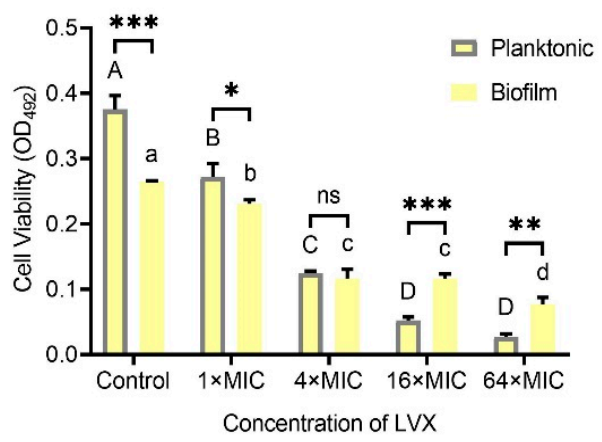

Figure 3. Eradication effects of CLR and LVX at $1 \times \mathrm{MIC}, 4 \times \mathrm{MIC}, 16 \times \mathrm{MIC}$, and $64 \times \mathrm{MIC}$ dilutions on $H$. pylori planktonic cells and mature biofilms. The experimental data are expressed as the mean \pm standard deviation $(n=3)$, and differences in viability between planktonic cells and mature biofilm cells with the same concentration of the same antibiotic are expressed with asterisks $\left.{ }^{*}\right){ }^{*}(p<0.05),{ }^{* *}(p<0.01)$, and ${ }^{* * *}(p<0.001)$, ns. non-significant. Differences in viability among planktonic cells with different concentrations of the same antibiotic are expressed with different capitalized superscript letters $(p<0.05)$. Differences in viability among biofilm cells with different concentrations of the same antibiotic are expressed with different lowercase superscript letters $(p<0.05)$.

\subsection{Combination of CFS and Different Antibiotics Can Influence the Viability of H. pylori Mature Biofilms}

Based on the fact that $H$. pylori improves its tolerance to CLR and LVX after biofilm formation, and that probiotic metabolites may improve the efficacy of antibiotic, we investigate the eradication effects of CFS and CLR, LVX alone, or CFS and antibiotics in combination on mature biofilms [16]. We used $1 \times$ MIC dilutions of antibiotics, the CFS dilution adjusted to $1 / 2 \times$ MIC, which was $6.25 \%$.

The biofilm viability of all experimental groups was significantly lower $(p<0.05)$ than that of the control group, except for the CLR $+1 / 2 \mathrm{CFS}$ group, for which the $\mathrm{OD}_{492 \mathrm{~nm}}$ was significantly higher than the $0.265 \pm 0.002$ of the control group, see Figure 4 . The strongest eradication capacity appeared in the 1/2CFS group, and the weakest eradication capacity was observed for the CLR $+1 / 2 \mathrm{CFS}$ group; the $\mathrm{OD}_{492 \mathrm{~nm}}$ values of these groups were $0.170 \pm 0.004$ and $0.304 \pm 0.032$, respectively. In the antibiotic-only groups, CLR was significantly more powerful than LVX in eradicating biofilms. However, when antibiotics were used in combination with CFS, the results were strikingly different. CLR, which had stronger eradication capacity than LVX when used alone, completely lost its ability to eradicate biofilms in combination with CFS, and the $\mathrm{OD}_{492 \mathrm{~nm}}$ was significantly higher in the combination group than in the CLR group and the 1/2CFS group. The eradication ability of the LVX $+1 / 2$ CFS group was significantly better than that of LVX alone, with $\mathrm{OD}_{492 \mathrm{~nm}}$ values of $0.179 \pm 0.016$ and $0.230 \pm 0.006$, respectively. However, the eradication ability of the LVX $+1 / 2$ CFS group was not significantly different from that of the $1 / 2$ CFS group. 


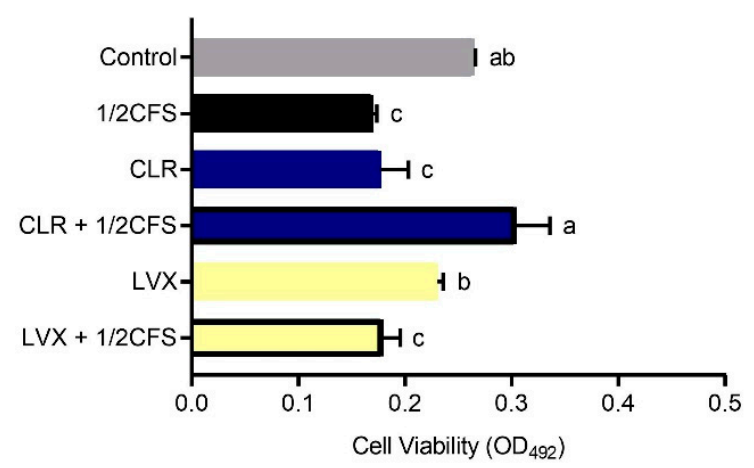

Figure 4. Eradication effects of a $1 / 2 \times$ MIC dilution of CFS, $1 \times$ MIC dilutions of CLR and LVX alone, and the same dilutions of CFS and antibiotic combinations on H. pylori mature biofilms. The experimental data are expressed as the mean \pm standard deviation $(n=3)$, and groups marked with different superscript letters are significantly different $(p<0.05)$.

\subsection{Combination of CFS and Different Antibiotics Can Affect the Protein and Polysaccharide Content of H. pylori Mature Biofilm EPS}

The concentration and combinations of CFS and antibiotics were referred to the viability assay. To determine the content of proteins and polysaccharides in biofilm EPS, we used the Bradford method and the phenol-sulfate method, respectively, and the content was calculated according to the standard curves.

As shown in Figure 5, the protein content measured in most experimental groups was significantly lower $(p<0.05)$ than that in the control group; however, the concentrations measured in the $1 / 2 \mathrm{CFS}$ and CLR $+1 / 2 \mathrm{CFS}$ groups were significantly higher than that in the control group. The 1/2CFS group had the highest protein content of $45.446 \pm 0.841 \mu \mathrm{g} / \mathrm{mL}$, and the control group had a content of $41.101 \pm 0.193 \mu \mathrm{g} / \mathrm{mL}$. The lowest content, $29.291 \pm 1.205 \mu \mathrm{g} / \mathrm{mL}$, was in the CLR group. When antibiotics were used alone, CLR had a stronger effect than LVX with regard to reducing the protein content of EPS. However, during combination treatment, we found that CFS significantly attenuated the effect of CLR on the reduction in protein content in EPS, and the protein concentration in this group was even higher than that in the control group. The opposite results were observed for the LVX $+1 / 2$ CFS group, with significantly lower protein content in the LVX $+1 / 2$ CFS group than in the LVX group or the $1 / 2$ CFS group, suggesting a possible additive effect of CFS and LVX.

The polysaccharide results were quite different from the protein results. The polysaccharide content measured in the LVX $+1 / 2$ CFS group was significantly lower than that in the control group $(p<0.05)$, but the polysaccharide content measured in the $1 / 2$ CFS group was not significantly different from that in the control group, and the remaining groups possessed significantly higher polysaccharide levels than the control group. The CLR $+1 / 2$ CFS group had the highest polysaccharide content among all groups at $208.38 \pm 8.51 \mu \mathrm{g} / \mathrm{mL}$, while the LVX $+1 / 2$ CFS group possessed the lowest polysaccharide concentration of $145.43 \pm 4.17 \mu \mathrm{g} / \mathrm{mL}$. Among the antibiotic-only groups, CLR had a weaker effect than LVX with regard to reducing the polysaccharide content in biofilm EPS. In the combination treatment, the CLR $+1 / 2 C F S$ group exhibited the greatest elevation in polysaccharide content in EPS, with a higher content than the 1/2CFS group and the CLR group. CFS intensified the LVX-mediated reduction in polysaccharide content; the polysaccharide concentration in the LVX $+1 / 2 C F S$ group was significantly lower than that in the LVX group and the $1 / 2 \mathrm{CFS}$ groups. 

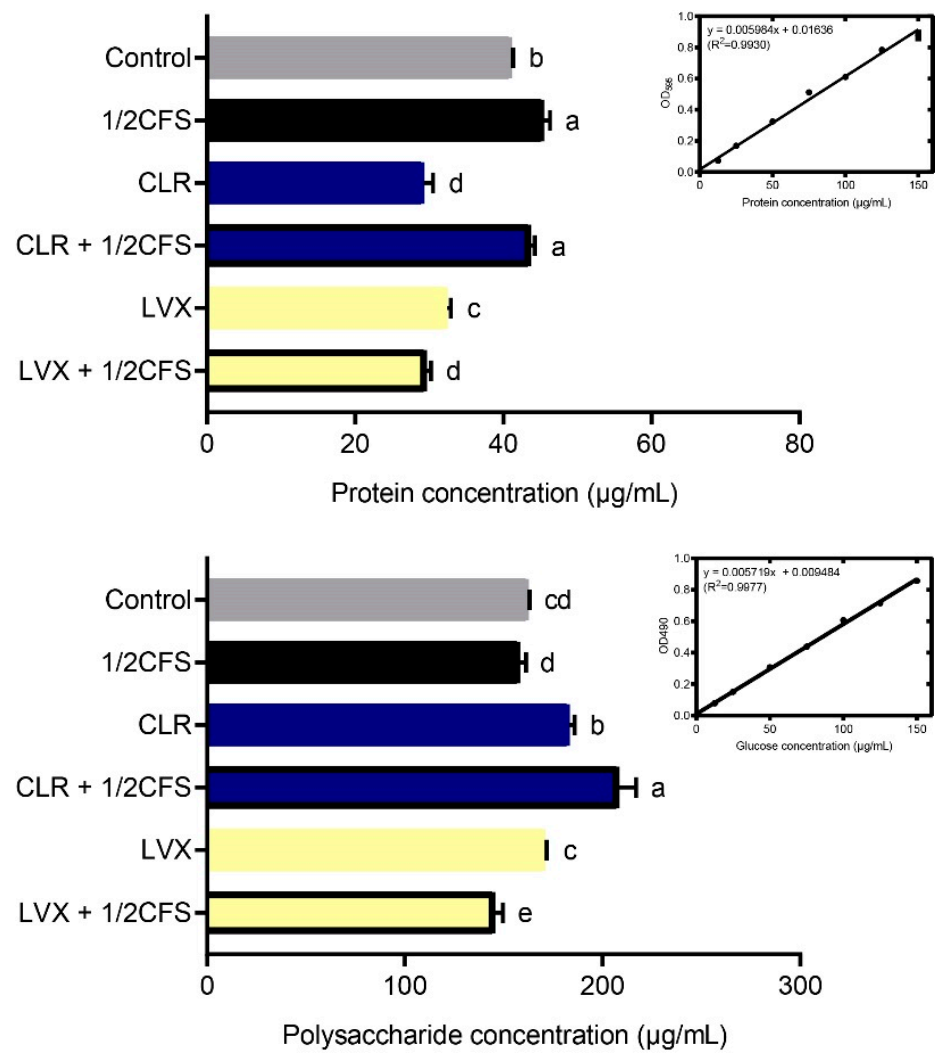

Figure 5. Effects of a 1/2 $\times$ MIC dilution of CFS, $1 \times$ MIC dilutions of CLR and LVX alone, or the same dilutions of CFS and antibiotic combinations on the protein and polysaccharide content of $H$. pylori mature biofilm EPS. The experimental data are expressed as the mean \pm standard deviation $(n=3)$, and groups marked with different superscript letters are significantly different $(p<0.05)$.

\subsection{SEM Observation of H. pylori Mature Biofilm Cell Morphology}

We used SEM to observe the morphology of $H$. pylori biofilm cells after $24 \mathrm{~h}$ of treatment. As shown in Figure 6, coccoid H. pylori cells were observed in all groups, but the CLR $+1 / 2$ CFS group presented the most spiral cells. In addition, $H$. pylori cells in different groups showed varying degrees of morphological damages.

Spiral and coccoid cells were more evenly distributed in the control group. The proportion of spiral cells in the 1/2CFS group was higher than that of the coccoid cells, and most coccoid cells in this group were damaged, while only a few spiral cells were damaged. In the CLR group, the proportion of spiral cells was slightly lower than that of the coccoid cells, and all the cells remained essentially intact, with the exception of a few coccoid cells that were damaged. There were many more spiral cells in the CLR $+1 / 2$ CFS group than in the CLR group, the 1/2CFS group, and the control group. The spiral cells in the CLR $+1 / 2$ CFS group all maintained cell integrity, while few of the remaining coccoid cells were damaged. Spiral and coccoid cells were evenly distributed in the LVX group, and only a small proportion of coccoid cells were damaged. More coccoid cells were present in the LVX $+1 / 2$ CFS group than in the LVX group and the $1 / 2 \times$ CFS group. The cells in this group showed severe damage, with some coccoid cells completely broken. 


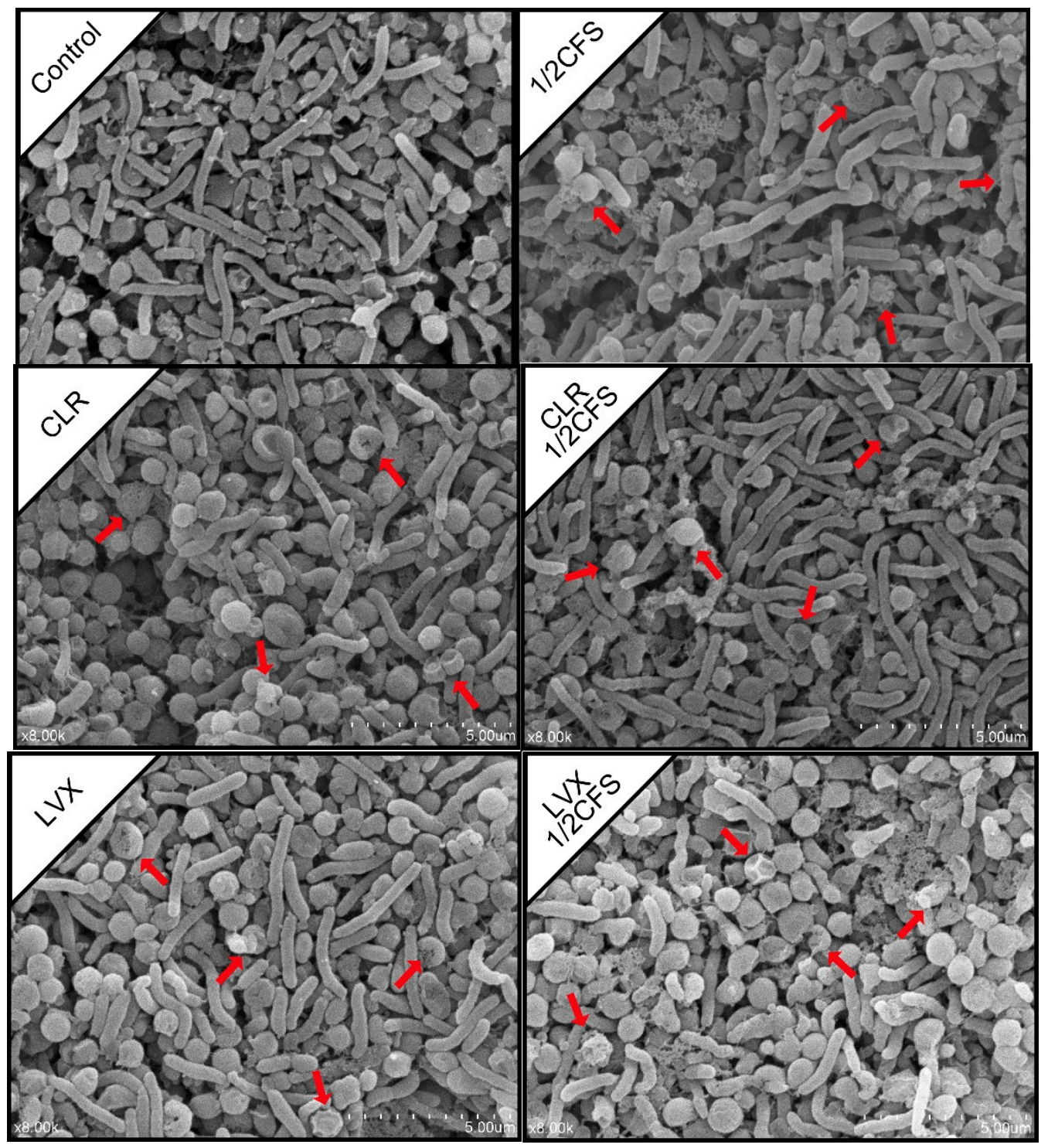

Figure 6. SEM images of a 1/2 $\times$ MIC dilution of CFS, $1 \times$ MIC dilutions of CLR and LVX alone, and the same dilutions of CFS and antibiotic combinations on H. pylori mature biofilm cell morphology. The magnification is $8000 \times$, and the scale bar is $5.00 \mu \mathrm{m}$. Red arrows indicate cells with morphological damages.

\subsection{CLSM Observation of H. pylori Mature Biofilm Structure}

The overall structure of $H$. pylori biofilm after $24 \mathrm{~h}$ of treatment was observed by CLSM. In Figure 7, green fluorescence represents all cells, and red fluorescence represents dead cells. A layer of dead cells appeared at the bottom of the biofilm near the NC membrane in all groups, and the thickness of the dead cell layer varied greatly among different groups. As shown in Table 4, the thickest live cell layer of experimental group was observed in the CLR $+1 / 2$ CFS group while the thinnest was observed in the $1 / 2$ CFS group, CLR group and the LVX $+1 / 2$ CFS group. The thickest dead cell layer was observed in the CLR group, and the thinnest was observed in the control group, $1 / 2 \mathrm{CFS}$ group and the LVX group. The cell staining images and the XTT results were almost identical in all groups, indicating that groups with thicker live cell layers possess greater viability and that those with thinner live cell layers possess lower viability. The live cell layer in the CLR group was evidently thinner than that in the CLR $+1 / 2 C F S$ group, and the LVX group had a significantly greater live cell layer thickness than the LVX $+1 / 2 C F S$ group. 

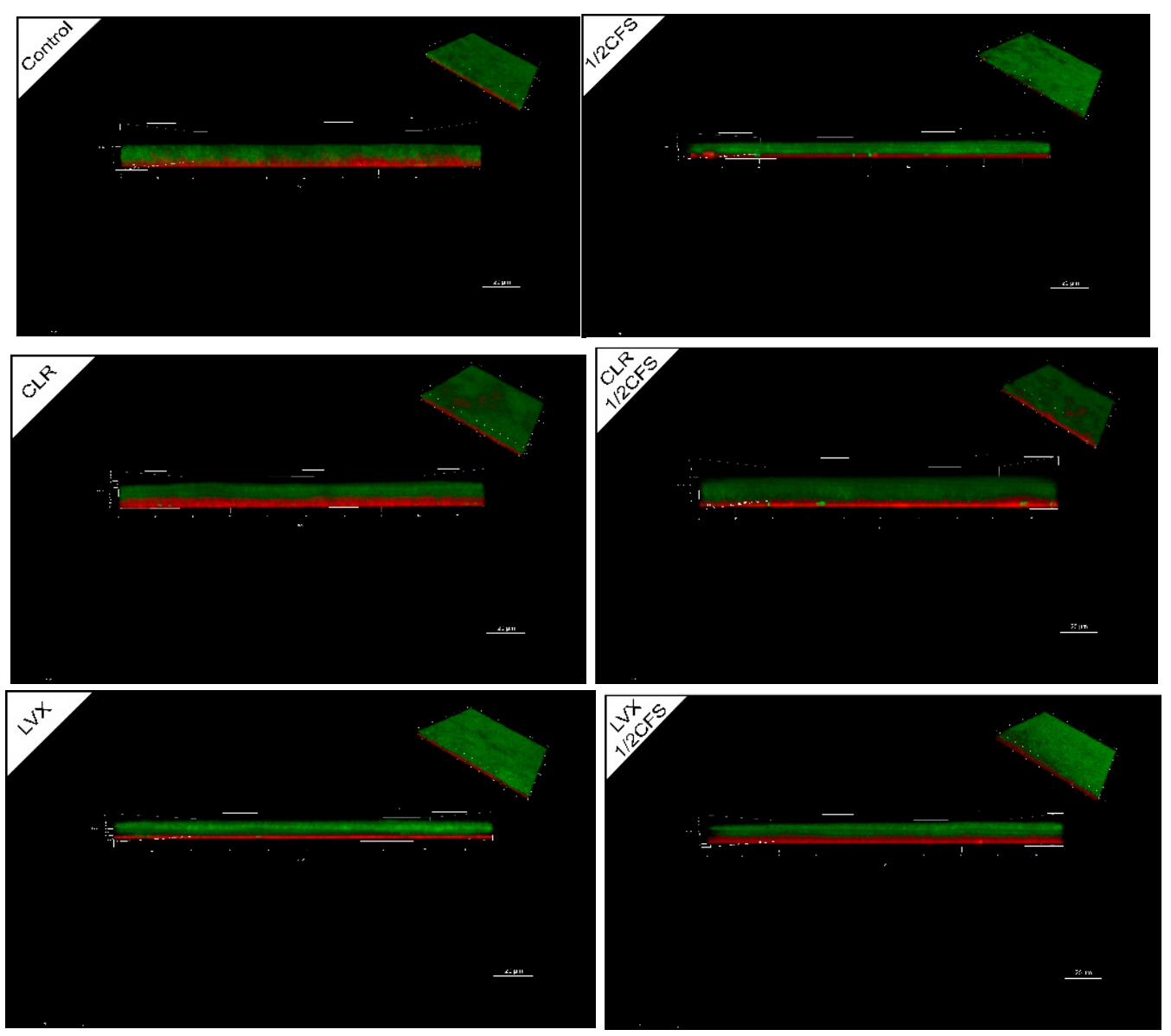

Figure 7. CLSM images of a $1 / 2 \times$ MIC dilution of CFS, $1 \times$ MIC dilutions of CLR and LVX alone, or the same dilutions of CFS and antibiotic combinations on $H$. pylori mature biofilm structure. All cells stained with SYTO 9 show green fluorescence, and dead cells stained with propidium iodide (PI) show red fluorescence. The bottom layer of the biofilm in the main view is close to the NC membrane surface. The front view shows the horizontal observations along the $x-y$ plane, and the scale bar is $20.00 \mu \mathrm{m}$.

Table 4. Thickness of biofilm observed by CLSM. The experimental data are expressed as the mean \pm standard deviation $(n=3)$, and differences in thickness among live cells are expressed with different lowercase superscript letters $(p<0.05)$. Differences in thickness among dead cells are expressed with different capitalized superscript letters $(p<0.05)$.

\begin{tabular}{ccc}
\hline Group & $\begin{array}{c}\text { Live Cells } \\
(\mathbf{n m})\end{array}$ & $\begin{array}{c}\text { Dead Cells } \\
(\mathbf{n m})\end{array}$ \\
\hline Control & $12.7 \pm 1.5 \mathrm{a}$ & $2.3 \pm 0.6 \mathrm{~B}$ \\
$1 / 2 \mathrm{CFS}$ & $6.7 \pm 0.6 \mathrm{c}$ & $1.7 \pm 0.6 \mathrm{~B}$ \\
CLR & $7.3 \pm 0.6 \mathrm{c}$ & $5.7 \pm 2.1 \mathrm{~A}$ \\
CLR $+1 / 2 \mathrm{CFS}$ & $11.7 \pm 1.2 \mathrm{ab}$ & $2.7 \pm 0.6 \mathrm{AB}$ \\
LVX & $9.3 \pm 1.5 \mathrm{bc}$ & $2.0 \pm 1.0 \mathrm{~B}$ \\
LVX $+1 / 2 \mathrm{CFS}$ & $6.7 \pm 1.2 \mathrm{c}$ & $4.3 \pm 1.5 \mathrm{AB}$ \\
\hline
\end{tabular}

3.8. Combined Treatment with CFS and Different Antibiotics Can Affect Virulence Gene Expression in H. pylori Biofilm Cells

For $H$. pylori biofilm cells after $24 \mathrm{~h}$ of treatment, we determined the relative expression of the $\operatorname{cag} A$ and $v a c A$ genes. As shown in Figure 8, the relative expression of the cag $A$ gene was significantly downregulated $(p<0.05)$ in all experimental groups compared with the control group. Among the experimental groups, the CLR group showed the weakest 
downregulation, whereas the rest of these groups were not significantly different from each other. The relative expression of $\operatorname{cag} A$ was significantly reduced by combined treatment with CLR and CFS compared with CLR alone; the relative expression was 0.807 times in the CLR group and 0.132 times in the CLR $+1 / 2$ CFS group. In addition, we found significant downregulation of $v a c A$ expression in all experimental groups compared to the control group. Among the combined CFS and antibiotic groups, the CLR $+1 / 2 C F S$ group was not significantly different compared with the CLR group. The relative expression of the vac $A$ gene in the LVX $+1 / 2$ CFS group was significantly lower than that in the LVX group.
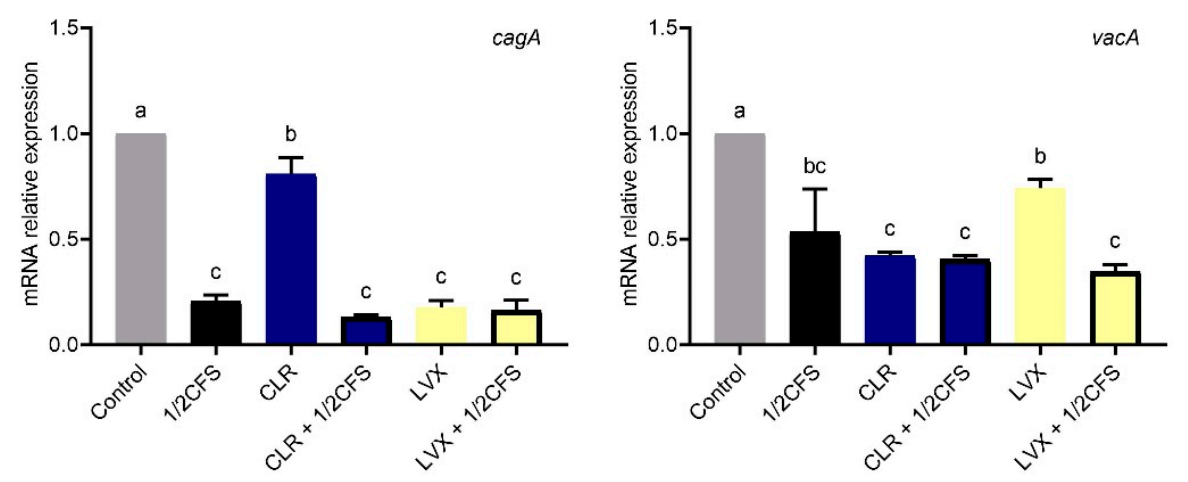

Figure 8. Effects of a $1 / 2 \times$ MIC dilution of CFS, $1 \times$ MIC dilutions of CLR and LVX alone, or the same dilutions of CFS and antibiotic combinations on $c a g A$ and vacA relative expression in $H$. pylori biofilm cells. The experimental data are expressed as the mean \pm standard deviation $(n=3)$, and groups marked with different superscript letters are significantly different $(p<0.05)$.

\subsection{Combined Treatment with CFS and Different Antibiotics Can Inhibit Live H. pylori Mature Biofilm Cell Dispersion}

In addition to determining the eradication effects of different combinations on $H$. pylori biofilms, we also evaluated the inhibitory effects of these combinations on live cell dispersion from biofilms by measuring the viability of cells in suspension after $24 \mathrm{~h}$ of biofilm eradication. As shown in Figure 9, the cell viability in the control group was highest, and the $\mathrm{OD}_{492 \mathrm{~nm}}$ values measured in the remaining groups were all significantly lower $(p<0.05)$ than the value in the control group.

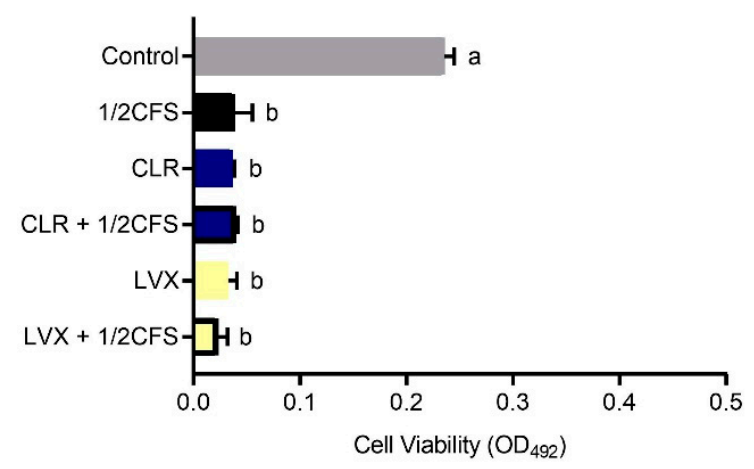

Figure 9. Effects of a 1/2 $\times$ MIC dilution of CFS, $1 \times$ MIC dilutions of CLR and LVX alone, or the same dilutions of CFS and antibiotic combinations on live H. pylori mature biofilm cell dispersion. The experimental data are expressed as the mean \pm standard deviation $(n=3)$, and groups marked with different superscript letters are significantly different $(p<0.05)$.

3.10. Combined Treatment with CFS and Different Antibiotics Can Influence the Viability of $H$. pylori Planktonic Cells

Finally, we determined the eradication effects of different combinations on H. pylori planktonic cells, and the results were similar to those measured in the biofilm cell assay. As shown in Figure 10, the cell viability measured in all experimental groups was significantly 
lower than that in the control group $(p<0.05)$. Among the antibiotics used alone, CLR was significantly more effective than LVX in eradicating planktonic cells. However, the cell viability of the CLR +1 /2CFS group was not significantly different from that of the LVX +1 /2CFS group. In addition, the viability of the CLR $+1 / 2$ CFS group was significantly higher than that of the CLR group, while the viability of the LVX $+1 / 2 C F S$ group was significantly lower than that of the LVX-only group.

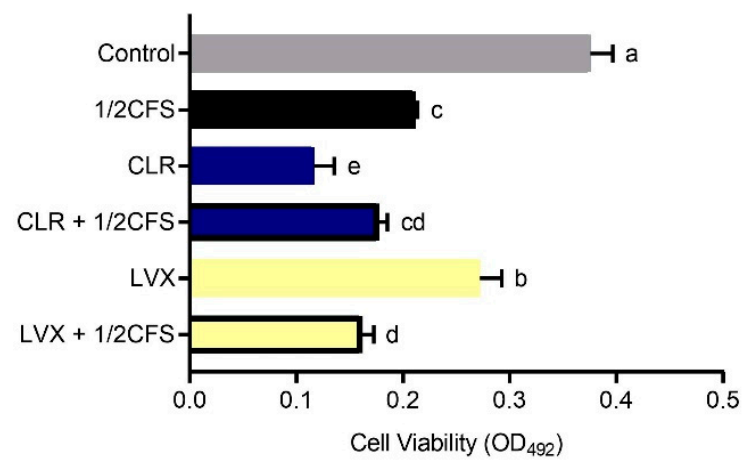

Figure 10. Effects of a $1 / 2 \times$ MIC dilution of CFS, $1 \times$ MIC dilutions of CLR and LVX alone, or the same dilutions of CFS and antibiotic combinations on H. pylori planktonic cell eradication. The experimental data are expressed as the mean \pm standard deviation $(n=3)$, and groups marked with different superscript letters are significantly different $(p<0.05)$.

\section{Discussion}

It is well known that $H$. pylori infection is associated with the development of a variety of gastrointestinal diseases. Clinical $H$. pylori eradication regimens usually use multidrug combination therapy, but the existence of multidrug-resistant strains and biofilms sometimes makes it difficult for therapies to achieve the optimal effects [22]. The emergence of multidrug-resistant strains may be related to inappropriate antibiotic use, and stubborn biofilms are natural barriers constructed by bacteria themselves against drugs and the host immune system [4]. A biofilm is defined as a bacterial population adhered to a substrate that is encapsulated by a layer of EPS, which is composed mainly of polysaccharides, proteins, and extracellular DNA (eDNA) secreted by bacteria [5]. Since the cells inside the biofilm are surrounded by EPS to form one entity, the total size exceeds the size that can be engulfed by immune cells such as neutrophils, thus enabling defense against the host immune system [23]. EPS also forms a barrier blocking antimicrobial drugs from reaching the cells inside. Cells encapsulated within EPS tend to have low metabolic rates accompanied by drug-efflux gene upregulation; these characteristics improve the resistance of the cells to death caused by antimicrobial drugs [5]. In vitro studies have demonstrated that the presence of a biofilm significantly increases the antibiotic resistance of $H$. pylori, with some strains exhibiting 4-fold and 40-fold higher MICs for clarithromycin and amoxicillin, respectively, among biofilm cells than among planktonic cells [24]. In our study, we investigated the sensitivity of $H$. pylori ATCC43504 before and after biofilm formation to CLR and LVX, two antibiotics that have been reported to be increasingly resisted in recent years [25]. As shown in Figure 3, the sensitivity of the H. pylori strain to high concentrations of CLR and LVX decreased significantly after mature biofilm formation. Unfortunately, biofilm cells may be prevalent in the gastric mucosae of $H$. pylori-infected patients. Coticchia et al. detected $H$. pylori biofilm density in the gastric mucosa of patients by endoscopy and SEM, and the results showed that the average biofilm coverage in urease test-positive patients was approximately $97.3 \%$, while the coverage in urease test-negative patients was merely $1.64 \%$ [26]. Thus, prevalent and stubborn biofilms may be pivotal interfering factors in $H$. pylori clinical eradication.

Probiotics, which are emerging biological preparations, have unique advantages of natural safety, immunomodulatory effects, flora-restoring abilities, and pathogenic bacteriaantagonizing effects and have the potential to help eradicate H. pylori biofilm cells [27]. 
Probiotics have been shown to inhibit pathogen biofilm formation by inhibiting pathogen growth, hindering pathogen adhesion and colonization, and interfering with the pathogen quorum sensing system [8]. Other studies have found that probiotics are able not only to inhibit pathogen biofilm formation but also to eradicate mature biofilms of bacteria such as Escherichia coli and Enterococcus faecalis [28,29]. Furthermore, there are many reports about probiotics such as L. plantarum, L. rhamnosus and L. acidophilus can antagonize H. pylori planktonic cells [30-32]. Additionally, these probiotics must tolerate the harsh environment of human gastric to provide an anti-H. pylori effect. Probiotics with high aggregation and hydrophobicity abilities are deemed to potentially colonize the human gastrointestinal environment [11]. Meanwhile, the $\mathrm{pH}$ in human stomach ranges from 1 to 4 and consists of pepsin, the candidate probiotics for $H$. pylori eradication must survive the extreme harsh environment [33]. In our study, we found that L. plantarum LN66 can survive at $\mathrm{pH} 2.0$ simulated gastric juice for $2 \mathrm{~h}$, and holds a moderate hydrophobicity and auto-aggregation capabilities (Supplementary Figures S2 and S3). Thus L. plantarum LN66 was selected for subsequent study. As shown in Figure 1, we found that CFS of LN66 was able to significantly eradicate the mature biofilm of H. pylori ATCC43504. Through a basic analysis of CFS effectiveness, we found that proteinase K enzymatic digestion had a significantly greater weakening effect on the eradication ability of CFS than neutralization, while heating has no significant effect on CFS eradication ability. Probiotics have been previously shown to be able to secrete lactic acid, short-chain fatty acids, bacteriocins, and other antagonistic antimicrobial substances to antagonize $H$. pylori [34]. Based on our results that the protein, polysaccharide, and $\mathrm{pH}$ value were significantly lower than MRS medium and reference strain (Supplementary Table S2), we tentatively speculate that the eradication effect of LN66 CFS on H. pylori biofilms may be mostly attributable to heat-stable short peptides, with some heat-stable organic acids playing a secondary role. In addition, as shown in Figure 2, the biofilm eradication ability of LN66 CFS was not very sensitive to low dilution factors; it still had strong eradication ability after being diluted 2- to 8-fold. This may be because CFS does not contain only one antibacterial substance. The additive effects of multiple antibacterial substances enable CFS to eradicate H. pylori biofilms at high dilutions. We consider L. plantarum LN66 as a potential applicable strain for improved eradication of H. pylori biofilms.

However, clinical results show that probiotics alone can merely reduce small loads of $H$. pylori in infected individuals and that the use of probiotics as adjuncts to supplement some antibiotic therapies may result in the desired effects [3]. In vitro experiments performed by Yang implied that Bifidobacterium breve YH68 CFS can improve the effectiveness of some antibiotics in inhibiting Clostridium difficile [16]. Soleymanzadeh et al. found that there are synergistic inhibitory effects between probiotics and tetracycline on clinical Pseudomonas aeruginosa strains [9]. Based on the finding that antibiotic sensitivity significantly decreased after $H$. pylori biofilm formation, and it is difficult for probiotic preparations alone to meet clinical needs, and there may be synergistic effects between probiotics and specific antibiotics. We investigated the differences in the effects of L. plantarum LN66 CFS, CLR and LVX acting separately or in combination on $H$. pylori mature biofilm eradication at the in vitro level. On the one hand, the FICs shows that the effect between CLR + CFS is antagonist, and the effect between LVX + CFS is additive. Additionally, the subsequent results showed that $L$. plantarum LN66 CFS significantly attenuated the eradication effect of CLR on H. pylori planktonic and biofilm cells, while there was some addictive effect between LN66 CFS and LVX. As shown in Figures 4 and 10, for either planktonic cells or biofilm cells, the eradication effect of CLR was significantly reduced when CLR was used in combination with CFS. The opposite results were obtained for the LVX-CFS combined treatment group; although the eradication effect of LVX in combination with CFS was not significantly better than that of CFS alone, it was significantly better than that of LVX alone. Thus, the results obtained in the LVX-CFS combined treatment group imply that the interaction between LVX and CFS is not antagonistic. Therefore, the possibility of co-use exists. Moreover, from the results of whole-biofilm cell staining shown in Figure 7, we can infer that the effects of 
CFS and CLR on biofilm eradication were antagonistic, whereas the effects of CFS and LVX were additive. The SEM results shown in Figure 6 reflect that most of the cells in the surface layer of the $H$. pylori biofilm transformed from coccoid cells to spiral cells when CLR and CFS were combined, whereas most surface cells transformed from spiral cells to coccoid cells when LVX and CFS were combined. Previous studies have shown that taking the coccoid form is a way for $H$. pylori cells to resist external pressure; this form appears when there are antibiotics or nutrient deficiencies in the environment and can be accompanied by DNA structure changes and specific gene expression [35]. For example, when H. pylori ATCC43504 is treated with a $4 \times$ MIC of lacticin A164, the majority of $H$. pylori cells transform from a spiral shape to a coccoid shape [36]. The transformation of surface biofilm cells from coccoid to spiral shapes may imply a decrease in the external pressure, which would also suggest that the eradication effects of LN66 CFS and CLR are antagonistic, whereas the eradication effects of LN66 CFS and LVX are additive. Furthermore, the CLSM results showed that the overall biofilm thickness and live cell thickness of the CLR $+1 / 2$ CFS group were higher than those of the rest of the groups, while the overall biofilm thickness and live cell thickness of the LVX $+1 / 2$ CFS group were lower than those of the rest of the groups. However, the overall thickness of the biofilm in the CLR and LVX groups was not significantly different before versus after combination with CFS, so the thickness of the biofilm may be influenced mainly by antibiotics. Thicker biofilms likely provide better defense for bacteria, while thinner biofilms may be helpful during clinical eradication. In addition, disruption of biofilms increases the risk of live bacteria dispersing into the surrounding environment and colonizing new surfaces, resulting in reinfection [37]. We determined the extent of live biofilm cell dispersion, as shown in Figure 9, and although there was an antagonistic effect between CLR and CFS in eradicating H. pylori biofilm, the combination was able to inhibit live biofilm cell dispersion as effectively as all the other treatments. We hypothesize that the improvement in efficacy exhibited by some probiotic supplementation therapies compared to traditional therapy in clinical trials and the lack of improvement exhibited by others is related to the different interactions between the probiotics and antibiotics used in the treatment.

The different interactions between CFS and CLR or LVX may be related to the different types of antibiotics and their mechanisms of action. CLR is a macrolide antibiotic that inhibits bacterial protein synthesis by reversibly binding to the $50 \mathrm{~S}$ ribosomal subunit, and LVX is a fluoroquinolone antibiotic that targets chromosome replication [25,38]. Their differences may allow the two antibiotics to achieve different effects on $H$. pylori biofilm EPS when combined with CFS. Li found that treating H. pylori mature biofilms with CLR alone could reduce the protein content of EPS by 34.8\% [5]. This phenomenon is consistent with our finding that the use of CLR alone was able to significantly reduce the protein content of H. pylori ATCC43504 mature biofilm EPS. However, when CLR was used in combination with CFS, its ability to reduce the EPS protein content was lost, and its ability to promote the EPS polysaccharide content was amplified. A thicker substrate, on the other hand, may have provided a better envelope in the CLR $+1 / 2$ CFS group, preventing killing by antimicrobial substances. LVX and CFS are more effective at disrupting biofilm EPS when combined than when used individually. Figure 5 shows that the combination of LVX and CFS reduced both the protein and polysaccharide content in EPS, and the change in matrix composition may have laid the foundation for the improved eradication effects of the antimicrobial substances. Therefore, CLR and CFS may not only be counteractive in eradicating $H$. pylori biofilms but also enhance the solidity of $H$. pylori biofilms when combined. On the other hand, although LVX and CFS in combination did not show an evident strong synergistic effect regarding biofilm eradication, they had a certain synergistic disrupting effect on the biofilm matrix.

The expression levels of $\operatorname{cag} A$ and $v a c A$, two main virulence genes of $H$. pylori, are often associated with gastrointestinal dysfunction and are related to inflammation, cytotoxicity and apoptosis [39]. Urrutia-Baca et al. found that treating H. pylori with reuterin, secreted by Lactobacillus reuteri, can downregulate the expression of the vacA virulence gene [40]. 
Our results showed that CFS, CLR, and LVX, which had eradication effects on H. pylori, could significantly downregulate $H$. pylori cagA and vacA gene expression. There was a synergistic effect between CFS and these two antibiotics in inhibiting cag $A$ and vacA expression. Thus, combination of LN66 with these two antibiotics may be helpful for alleviating the gastrointestinal dysfunction caused by H. pylori infection.

\section{Conclusions}

H. pylori biofilms are an obstacle to the clinical treatment of patients. Previous studies have shown that combinations of CLR and alginate lyase, LVX and bovine lactoferrin, and LVX and Pistacia vera L. oleoresin can inhibit $H$. pylori synergistically [41-43]. In our study, we investigated the different effects of CLR or LVX when used alone or in combination with L. plantarum LN66 CFS, which has anti-H. pylori capability, with regard to eradicating $H$. pylori mature biofilms. The results showed that combined treatment with CFS attenuated the eradication effect of CLR on H. pylori mature biofilms, while combined treatment with CFS promoted the disruptive effect of LVX on the H. pylori biofilm matrix. In addition, combined treatment with CFS and antibiotics had significant downregulatory effects on the expression levels of $H$. pylori biofilm virulence genes. Taking the clinical results of probiotic supplementation therapy into account, we believe that the use of L. plantarum LN66 as a supplementation may have the opposite effect during $H$. pylori treatment with CLR. The addition of L. plantarum LN66 may improve the eradication effects on $\mathrm{H}$. pylori biofilms when using therapy involving LVX. However, the underlying mechanism by which LN66 CFS exhibits different interactions with CLR and LVX still needs to be thoroughly investigated, and further cell and animal experiments are needed to validate the mechanism. It is worth considering whether this probiotic-antibiotic mode of action is strain- and antibiotic-specific and determining which probiotics can act synergistically with antibiotics to support $H$. pylori clinical eradication.

Supplementary Materials: The following are available online at https:/ /www.mdpi.com/2076-260 7/9/2/424/s1, Figure S1: Phylogenetic relationship of LN66, Figure S2: Survival of LAB strains after $2 \mathrm{~h}$ in $\mathrm{pH} 2.0$ simulated gastric acid, Figure S3: Auto-aggregation and hydrophobicity ability of four LAB strains, Table S1: Antagonistic abilities of LN66 CFS against five pathogens, Table S2: Protein, polysaccharide content and $\mathrm{pH}$ of LN66 CFS.

Author Contributions: Conceptualization, J.J.; Methodology, J.J.; Resources, H.Y.; Writing—original draft preparation, J.J.; writing—review and editing, H.Y.; Visualization, J.J.; Supervision, H.Y.; Project administration, H.Y.; Funding acquisition, H.Y. All authors have read and agreed to the published version of the manuscript.

Funding: This work was funded by Shanghai Industry-University Joint Research Program, grant numbers HUCXY-2016-010.

Institutional Review Board Statement: Not applicable.

Informed Consent Statement: Not applicable.

Data Availability Statement: Data is contained within the article and supplementary material.

Acknowledgments: The authors would like to thank Jingpeng Yang, Fang Jin from Shanghai Jiao Tong University for providing suggestions.

Conflicts of Interest: The authors declare no conflict of interest.

\section{References}

1. O'Connor, A.; O'Morain, A.O.C.A.; Ford, A.O.A.C. Population screening and treatment of Helicobacter pylori infection. Nat. Rev. Gastroenterol. Hepatol. 2017, 14, 230-240. [CrossRef] [PubMed]

2. Wroblewski, L.E.; Peek, R.M.; Wilson, K.T. Helicobacter pylori and Gastric Cancer: Factors That Modulate Disease Risk. Clin. Microbiol. Rev. 2010, 23, 713-739. [CrossRef] [PubMed]

3. Ji, J.; Yang, H. Using Probiotics as Supplementation for Helicobacter pylori Antibiotic Therapy. Int. J. Mol. Sci. 2020, 21, 1136. [CrossRef] 
4. Hathroubi, S.; Servetas, S.L.; Windham, I.; Merrell, D.S.; Ottemann, K.M. Helicobacter pylori Biofilm Formation and Its Poten-tial Role in Pathogenesis. Microbiol. Mol. Biol. Rev. 2018, 82, e00001-e00018. [CrossRef] [PubMed]

5. Li, P.; Chen, X.; Shen, Y.; Li, H.; Zou, Y.; Yuan, G.; Hu, P.; Hu, H. Mucus penetration enhanced lipid polymer nanoparticles improve the eradication rate of Helicobacter pylori biofilm. J. Control. Release 2019, 300, 52-63. [CrossRef]

6. Mathur, H.; Field, D.; Rea, M.C.; Cotter, P.D.; Hill, C.; Ross, R.P. Fighting biofilms with lantibiotics and other groups of bacteriocins. npj Biofilms Microbiomes 2018, 4, 9. [CrossRef]

7. Yang, J.; Yang, H. Transcriptome Analysis of the Clostridioides difficile Response to Different Doses of Bifidobacterium breve. Front. Microbiol. 2020, 11, 1863. [CrossRef] [PubMed]

8. Barzegari, A.; Kheyrolahzadeh, K.; Khatibi, S.M.H.; Sharifi, S.; Memar, M.Y.; Vahed, S.Z. The Battle of Probiotics and Their Derivatives against Biofilms. Infect. Drug Resist. 2020, 13, 659-672. [CrossRef]

9. Moghadam, S.S.; Khodaii, Z.; Zadeh, S.F.; Ghooshchian, M.; Aghmiyuni, Z.F.; Shabestari, T.M.; Ghoshchiyan, M. Synergistic or Antagonistic Effects of Probiotics and Antibiotics- Alone or in Combination- on Antimicrobial-Resistant Pseudomonas aeruginosa Isolated from Burn Wounds. Arch. Clin. Infect. Dis. 2018, 13, 63121. [CrossRef]

10. Miao, J.; Xin, L.; Wu, Z.; Guo, B. Studies on Modified MRS Eliminating the Inhibited Growth of Helicobacter pylori Caused by MRS Self. J. Dairy Sci. Technol. 2005, 4, 154-156. (In Chinese)

11. De Souza, B.M.S.; Borgonovi, T.F.; Casarotti, S.N.; Todorov, S.D.; Penna, A.L.B. Lactobacillus casei and Lactobacillus fermentum Strains Isolated from Mozzarella Cheese: Probiotic Potential, Safety, Acidifying Kinetic Parameters and Viability under Gastrointestinal Tract Conditions. Probiotics Antimicrob. Proteins 2019, 11, 382-396. [CrossRef]

12. Zuo, F.; Yu, R.; Feng, X.; Chen, L.; Zeng, Z.; Khaskheli, G.B.; Ma, H.; Chen, S. Characterization and in vitro properties of po-tential probiotic Bifidobacterium strains isolated from breast-fed infant feces. Ann. Microbio. 2015, 66, 1027-1037. [CrossRef]

13. Al-Malkey, M.K.; Ismeeal, M.C.; Al-Hur, F.J.A.; Mohammed, S.W.; Nayyef, H.J. Antimicrobial effect of probiotic Lactobacillus spp. on Pseudomonas aeruginosa. J. Contemp. Med. Sci. 2017, 3, 218-223.

14. Bomfim, V.B.; Neto, J.H.P.L.; Leite, K.S.; de Andrade Vieira, É.; Iacomini, M.; Mellinger-Silva, C.; Dos Santos, K.M.; Cardarelli, H.R. Partial characterization and antioxidant activity of exopolysaccharides produced by Lactobacillus plantarum CNPC003. LWT 2020, 127, 109349. [CrossRef]

15. Pelyuntha, W.; Chaiyasut, C.; Kantachote, D.; Sirilun, S. Cell-free supernatants from cultures of lactic acid bacteria isolated from fermented grape as biocontrol againstSalmonellaTyphi andSalmonellaTyphimurium virulence via autoinducer-2 and biofilm interference. PeerJ 2019, 7, e7555. [CrossRef] [PubMed]

16. Yang, J.; Yang, H. Effect of Bifidobacterium breve in Combination with Different Antibiotics on Clostridium difficile. Front. Microbiol. 2018, 9, 2953. [CrossRef] [PubMed]

17. Ge, X.; Cai, Y.; Chen, Z.; Gao, S.; Geng, X.; Li, Y.; Li, Y.; Jia, J.; Sun, Y. Bifunctional enzyme SpoT is involved in biofilm for-mation of Helicobacter pylori with multidrug resistance by upregulating efflux pump Hp1174 (gluP). Antimicrob. Agents Chemother. 2018, 62, e00957-18. [CrossRef] [PubMed]

18. Chen, X.; Liu, X.M.; Tian, F.; Zhang, Q.; Zhang, H.P.; Zhang, H.; Chen, W. Antagonistic activities of lactobacilli against Helicobacter pylori growth and infection in human gastric epithelial cells. J. Food Sci. 2012, 77, 9-14. [CrossRef]

19. Cerca, N.; Martins, S.; Cerca, F.; Jefferson, K.K.; Pier, G.B.; Oliveira, R.; Azeredo, J. Comparative assessment of antibiotic susceptibility of coagulase-negative staphylococci in biofilm versus planktonic culture as assessed by bacterial enumeration or rapid XTT colorimetry. J. Antimicrob. Chemother. 2005, 56, 331-336. [CrossRef]

20. Kang, J.; Liu, L.; Liu, Y.; Wang, X. Ferulic Acid Inactivates Shigella flexneri through Cell Membrane Destructieon, Biofilm Retardation, and Altered Gene Expression. J. Agric. Food Chem. 2020, 68, 7121-7131. [CrossRef]

21. Franklin, M.J.; Chang, C.; Akiyama, T.; Bothner, B. New Technologies for Studying Biofilms. Microbiol. Spectr. 2015, 3, 4. [CrossRef]

22. Yu, M.; Wang, X.; Ling, F.; Wang, H.; Zhang, P.; Shao, S. Atractylodes lancea volatile oils attenuated Helicobacter pylori NCTC11637 growth and biofilm. Microb. Pathog. 2019, 135, 103641. [CrossRef] [PubMed]

23. Yan, J.; Bassler, B.L. Surviving as a Community: Antibiotic Tolerance and Persistence in Bacterial Biofilms. Cell Host Microbe 2019, 26, 15-21. [CrossRef] [PubMed]

24. Cai, Y.; Wang, C.; Chen, Z.; Xu, Z.; Li, H.; Li, W.; Sun, Y. Transporters HP0939, HP0497, and HP0471 participate in intrinsic multidrug resistance and biofilm formation in Helicobacter pylori by enhancing drug efflux. Helicobacter 2020, 25, e12715. [CrossRef]

25. Thung, I.; Aramin, H.; Vavinskaya, V.; Gupta, S.; Park, J.Y.; Crowe, S.E.; Valasek, M.A. Review article: The global emergence of Helicobacter pylori antibiotic resistance. Aliment. Pharmacol. Ther. 2016, 43, 514-533. [CrossRef] [PubMed]

26. Coticchia, J.M.; Sugawa, C.; Tran, V.R.; Gurrola, J.; Kowalski, E.; Carron, M.A. Presence and density of Helicobacter pylori bio-films in human gastric mucosa in patients with peptic ulcer disease. J. Gastrointest. Surg. 2006, 10, 883-889. [CrossRef]

27. Suez, J.; Zmora, N.; Segal, E.; Elinav, E. The pros, cons, and many unknowns of probiotics. Nat. Med. 2019, 25, 716-729. [CrossRef]

28. Jung, S.; Park, O.J.; Kim, A.R.; Ahn, K.B.; Lee, D.; Kum, K.Y.; Yun, C.H.; Han, S.H. Lipoteichoic acids of lactobacilli inhibit En-terococcus faecalis biofilm formation and disrupt the preformed biofilm. J. Microbiol. 2019, 57, 310-315. [CrossRef]

29. Song, H.; Zhang, J.; Qu, J.; Liu, J.; Yin, P.; Zhang, G.; Shang, D. Lactobacillus rhamnosus GG microcapsules inhibit Escherichia coli biofilm formation in coculture. Biotechnol. Lett. 2019, 41, 1007-1014. [CrossRef] [PubMed]

30. Zhao, K.; Xie, Q.; Xu, D.; Guo, Y.; Tao, X.; Wei, H.; Wan, C. Antagonistics of Lactobacillus plantarum ZDY2013 against Helicobacter pylori SS1 and its infection in vitro in human gastric epithelial AGS cells. J. Biosci. Bioeng. 2018, 126, 458-463. [CrossRef] 
31. Chen, M.E.; Su, C.H.; Yang, J.S.; Lu, C.C.; Hou, Y.C.; Wu, J.B.; Hsu, Y.M. Baicalin, Baicalein, and Lactobacillus Rhamnosus JB3 Alleviated Helicobacter pylori Infections in vitro and in vivo. J. Food. Sci. 2018, 83, 3118-3125. [CrossRef]

32. Chen, Y.-H.; Tsai, W.-H.; Wu, H.-Y.; Chen, C.-Y.; Yeh, W.-L.; Chen, Y.-H.; Hsu, H.-Y.; Chen, W.-W.; Chen, Y.-W.; Chang, W.-W.; et al. Probiotic Lactobacillus spp. act Against Helicobacter pylori-induced Inflammation. J. Clin. Med. 2019, 8, 90. [CrossRef]

33. Chen, X.; Tian, F.; Liu, X.; Zhao, J.; Zhang, H.-P.; Chen, W.; Zhang, H. In Vitro screening of lactobacilli with antagonistic activity against Helicobacter pylori from traditionally fermented foods. J. Dairy Sci. 2010, 93, 5627-5634. [CrossRef]

34. Homan, M.; Orel, R. Are probiotics useful in Helicobacter pylori eradication? World J. Gastroenterol. 2015, 21, 10644-10653. [CrossRef]

35. Kadkhodaei, S.; Siavoshi, F.; Akbari Noghabi, K. Mucoid and coccoid Helicobacter pylori with fast growth and antibiotic re-sistance. Helicobacter 2020, 25, e12678. [CrossRef] [PubMed]

36. Kim, T.S.; Hur, J.W.; Yu, M.A.; Cheigh, C.I.; Kim, K.N.; Hwang, J.K.; Pyun, Y.R. Antagonism of Helicobacter pylori by bacteri-ocins of lactic acid bacteria. J. Food Prot. 2003, 66, 3-12. [CrossRef] [PubMed]

37. Chen, X.; Li, P.; Shen, Y.; Zou, Y.; Yuan, G.; Hu, H. Rhamnolipid-involved antibiotics combinations improve the eradication of Helicobacter pylori biofilm in vitro: A comparison with conventional triple therapy. Microb. Pathog. 2019, 131, 112-119. [CrossRef] [PubMed]

38. Hanafi, A.; Lee, W.C.; Loke, M.F.; Teh, X.; Shaari, A.; Dinarvand, M.; Lehours, P.; Mégraud, F.; Leow, A.H.R.; Vadivelu, J.; et al. Molecular and Proteomic Analysis of Levofloxacin and Metronidazole Resistant Helicobacter pylori. Front. Microbiol. 2016, 7, 2015. [CrossRef] [PubMed]

39. Salama, N.R.; Hartung, M.L.; Muller, A. Life in the human stomach: Persistence strategies of the bacterial pathogen Helicobacter pylori. Nat. Rev. Microbiol. 2013, 11, 385-399. [CrossRef]

40. Urrutia-Baca, V.H.; Escamilla-García, E.; De La Garza-Ramos, M.A.; Tamez-Guerra, P.; Gomez-Flores, R.; Urbina-Ríos, C.S. In Vitro Antimicrobial Activity and Downregulation of Virulence Gene Expression on Helicobacter pylori by Reuterin. Probiotics Antimicrob. Proteins 2018, 10, 168-175. [CrossRef] [PubMed]

41. Ciccaglione, A.F.; Di Giulio, M.; Di Lodovico, S.; Di Campli, E.; Cellini, L.; Marzio, L. Bovine lactoferrin enhances the effi-cacy of levofloxacin-based triple therapy as first-line treatment of Helicobacter pylori infection: An in vitro and in vivo study. J. Antimicrob. Chemother. 2019, 74, 1069-1077. [CrossRef]

42. Di Lodovico, S.; Napoli, E.; Di Campli, E.; Di Fermo, P.; Gentile, D.; Ruberto, G.; Nostro, A.; Marini, E.; Cellini, L.; Di Giulio, M. Pistacia vera L. oleoresin and levofloxacin is a synergistic combination against resistant Helicobacter pylori strains. Sci. Rep. 2019, 9, 1-10. [CrossRef]

43. Bugli, F.; Palmieri, V.; Torelli, R.; Papi, M.; De Spirito, M.; Cacaci, M.; Galgano, S.; Masucci, L.; Paroni Sterbini, F.; Vella, A.; et al. In vitro effect of clarithromycin and alginate lyase against Helicobacter pylori biofilm. Biotechnol. Prog. 2016, 32, $1584-1591$. [CrossRef] 